\title{
Candida Endocarditis: A Review of the Pathogenesis, Morphology, Risk Factors, and Management of an Emerging and Serious Condition
}

Sahil Mamtani ${ }^{1,2,3}$, Nawar Muneer Aljanabi ${ }^{2}$, Robins P. Gupta Rauniyar ${ }^{4}$, Ashu Acharya ${ }^{2}$, Bilal Haider Malik $^{2}$

1. Infectious Diseases Research, Veterans Affairs Medical Center, Lebanon, USA 2. Internal Medicine, California Institute of Behavioral Neurosciences and Psychology, Fairfield, USA 3. Research, Jacobi Medical Center, Bronx, USA 4. Surgery, California Institute of Behavioral Neurosciences and Psychology, Fairfield, USA

Corresponding author: Sahil Mamtani, sahil.mamtani@gmail.com

\begin{abstract}
Infective endocarditis is a significant healthcare burden due to the associated high mortality and complications. Endocarditis caused by both Candida albicans (C. albicans) and non-Candida albicans Candida (NCAC) species has been associated with a substantial rise in in-hospital morbidity and mortality. We used the Pubmed database to identify 47 out of 101 articles that had met our inclusion and exclusion criteria. We had put in place a broad inclusion criterion with no age or gender restrictions. These 47 articles included abstracts, 11 review articles, 13 case reports, 10 research articles, 1 clinical trial report, 1 meta-analysis, and other research articles. And they comprehensively cover the pathogenesis, risk factors, and management of infections caused by C. albicans and NCAC species in the past 26 years. The articles we scanned provided us with information on different associations in correlation to multiple types of Candida species. Here, we discuss the association between Candida and endocarditis, a major cause of morbidity and mortality in both C. albicans and NCAC. We also present our understanding regarding this interesting association and attempt to address some of the recurring questions.
\end{abstract}

Received 12/17/2019

Review began 01/12/2020 Review ended 01/14/2020 Published 01/18/2020

(c) Copyright 2020 Mamtani et al. This is an open access article distributed under the terms of the Creative Commons Attribution License CC-BY 3.0., which permits unrestricted use, distribution, and reproduction in any medium, provided the original author and source are credited.
Categories: Internal Medicine, Pathology, Infectious Disease

Keywords: c albicans, endocarditis, candidemia, prosthetic heart valves, candidiasis, infective, candida, non candida albicans candida, c parapsilosis, catheter related blood stream infections

\section{Introduction And Background}

Infective endocarditis is a significant healthcare burden due to the associated high mortality and subsequent complications. According to a prospective cohort study by the International Collaboration on Endocarditis (ICE), the current six-month mortality rate for the condition is approximately $25 \%$. It is an emerging trend throughout the world, in both developing and developed countries, despite the widespread availability of modern diagnostic and treatment methods [1]. The in-hospital mortality rate and readmission rate related to the condition are on a dangerous upward trend [2-4]. Fungal endocarditis accounts for 1-6\% of the total endocarditis spectrum. It has a significant association with prosthetic heart valves and devices and a more extended postoperative recovery period. It also increases the potential risk of congestive heart failure, intravenous drug use (IVDU), catheter use, prolonged antibiotic therapy, and many other maladies [5-25]. In particular, the Candida species has been associated with a substantial increase in in-hospital morbidity and mortality [5].

Recent literature on non-Candida albicans Candida (NCAC) species involving prosthetic devices and hemodialysis catheters have suggested that these could constitute an independent risk factor in candidiasis [26]. There are still many missing pieces, such as the question as to whether the Candida species prefer a specific heart valve area compared to non-fungal endocarditis. Also, It is not clear if any of the risk factors, either combined or individually, predisposes the patient to Candida endocarditis. In this review, we examine case reports and previous literature reviews of different Candida species to ascertain the troubling association between Candida and endocarditis with a high level of urgency. Moreover, IVDU and the rise of candidemia are rising and problematic trends to consider [8]. We also discuss the complications of postoperative recovery compared to medical treatment alone in this literature review. Candida endocarditis is an emerging disease and a growing health concern globally, especially among the elderly population and immunosuppressed [23]. Additionally, patients needing long-term hospital care with indwelling devices and catheters often suffer from unwanted life-threatening nosocomial infections [10]. Some medications have displayed outcomes outlined in standard guidelines in particular species of Candidia and are reviewed in this article [27]. Anatomically, we perceive that location is one of the factors indicated in the invasion [28]. Genetics often plays a significant role in the attack of a host cell [29-31]. We believe the varied pathology will help us understand the divergent ways of NCAC species [32-38]. Finally, we examine the various diagnostic methods, including echocardiography, and management of the disease, including current and 
changing guidelines in candidiasis treatment $[39,40]$. We hope that a rigorous look at the facts presented in this review will foster awareness that will contribute to curbing mortality rates associated with the disease.

\section{Review}

The fungal species in Candida fall under two categories: Candida albicans (C. albicans) and NCAC [30,31]. Most species from the Candida genus can be found as healthy skin and mucocutaneous commensals and are often present throughout life. To date, only C. albicans and few other NCAC species such as C. auris, $C$. glabrata, C. parapsilosis, C. tropicalis, C. guilliermondii, C. krusei, and C. dubliniensis have known to act as human pathogens involved in diseases [31]. However, the characteristics, morphogenesis, and pathogenesis differ significantly even within the Candida species [12,32-34]. Some authors have suggested an association between certain Candida species and particular types of patients. For example, C. dubliniensis is associated with human immunodeficiency virus (HIV)-positive individuals with oral thrush, whereas C. parapsilosis has been associated with patients who undergo transcatheter aortic valve replacement (TAVR), transplant recipients, and patients on parenteral nutrition (PN). Moreover, C. parapsilosis has been identified as the second most common species to be isolated from blood culture, the most common being C. albicans [35].

\section{Morphological differences between Candida albicans and non- Candida albicans Candida species}

There are close to 150 heterogenous Candida species. However, only a few can survive the normal human body temperature of $37^{\circ} \mathrm{C}$ to establish themselves as human pathogens or commensals. To the naked eye, Candida colonies appear creamy yellow and seem to have yeast-like morphology. Microscopically, most species of Candida grow in the log phase to approximately 3x7 um in size and look like budding yeasts. Some Candida species, such as C. albicans and C. dubliniensis, often produce true hyphae or pseudohyphae. Pseudohyphae are elongated projections from parent cells restricted by cell-to-cell junctions. True hyphae, on the other hand, do not display cell-to-cell junctions; instead, they are elongated cells [35]. C. dubliniensis is less virulent in comparison to C. albicans, leaving less room for an invasion. It has been reported that evolutionary changes in specific gene sequences and the hyphally regulated gene (HYR1) result in decreased pathogenicity of $C$. dubliniensis. The changes in genetic sequences allow us to understand the pertinent factors playing a role in establishing the disease [30]. C. parapsilosis is another NCAC species that can form pseudohyphae, which are larger and called "giant cells." [12,27]. C. tropicalis displays yeast and pseudohyphal growth in Tween 80 and at $37^{\circ} \mathrm{C}$ for 48 hours [36]. C. glabrata is not polymorphic and was not considered a human pathogen earlier. However, due to increasing conditions of immunosuppression and broad-spectrum antibiotic use, C. glabrata has emerged as an opportunistic pathogen. Being much smaller in size (around 1-4 um) compared to other pathogenic Candida species and being of haploid strain, C. glabrata has now become more noticed [26-29,37]. Figure 1 below lays out the differences between the various Candida species.

\begin{tabular}{|c|c|c|c|c|c|}
\hline & C. albicans & C. tropicalis & C. parapsilosis & C. dublinensis & C. glabrata \\
\hline Appearance & Creamy yellow & $\begin{array}{l}\text { Creamy w/ } \\
\text { mycelial border }\end{array}$ & Creamy yellow & Creamy yellow & Creamy yellow \\
\hline Microscopy & $3 \times 7 \mu \mathrm{m}$ & $4-8 \mu \mathrm{m}$ & $2.5-4 \mu \mathrm{m}$ & $3 \times 7 \mu \mathrm{m}$ & $1-4 \mu \mathrm{m}$ \\
\hline Hyphae & $\begin{array}{l}\text { Can form hyphae } \\
\text { and } \\
\text { pseudohyphae }\end{array}$ & $\begin{array}{l}\text { May form } \\
\text { pseudohyphae, } \\
\text { oval } \\
\text { blastospores, } \\
\text { and even true } \\
\text { hyphae }\end{array}$ & $\begin{array}{l}\text { No true hyphae- } \\
\text { forms } \\
\text { pseudohyphae } \\
\text { known as "giant } \\
\text { cells" }\end{array}$ & $\begin{array}{l}\text { Forms hyphae } \\
\text { and } \\
\text { pseudohyphae }\end{array}$ & Cannot form \\
\hline Risk factors & $\begin{array}{l}\text { High virulence } \\
\text { IV drug users } \\
\text { Immunosuppressi } \\
\text { on }\end{array}$ & $\begin{array}{l}\text { Defibrillators } \\
\text { Young age/ } \\
\text { neonates } \\
\text { Vertical }\end{array}$ & $\begin{array}{l}\text { Prosthetic } \\
\text { devices/valves } \\
\text { TAVR } \\
\text { Previous }\end{array}$ & $\begin{array}{l}\text { HIV with oral } \\
\text { thrush }\end{array}$ & $\begin{array}{l}\text { Immunosuppresi } \\
\text { on } \\
\text { Broad spectrum } \\
\text { antibiotics }\end{array}$ \\
\hline
\end{tabular}

FIGURE 1: Candida albicans vs. non-Candida albicans Candida species

TAVR: transcatheter aortic valve replacement; HIV: human immunodeficiency virus

\section{Mode of transmission}

Inoculation is different for many of these species. For example, In C. parapsilosis, horizontal transmission 
through infected medical devices, transmission through the hands of healthcare workers, and the use of catheters accounted for a large amount of invasive infection in neonates. In contrast, in C. albicans and C. tropicalis, infection in neonates was more frequently through vertical transmission [27]. Fungal invasive infections caused by $C$. parapsilosis often occur through central venous lines and hyperalimentation solutions (parenteral nutrition) due to its increased preference and growth capacity [27,38]. Also, a recent Spanish study of invasive $C$. parapsilosis showed that prolonged vascular catheterization and prior surgery were some of the most critical risk factors [27]. C. tropicalis is more commonly associated with malignancy and neutropenia, and consequently with a higher mortality rate [38]. The pathogenesis of certain NCAC species, such as $C$. tropicalis, can also be fatal due to their more elevated virulence-associated markers. For example, biofilm formation and secretion of proteinases in C. tropicalis can create an impactful and invasive infection compared to C. albicans [27,41]. In a study by Negri et al., C. tropicalis adhered more strongly to epithelial cells than silicone, indicating easier dissemination and invasion [41].

\section{Colonization}

Skin and gastrointestinal (GI) tract colonization is one of the first steps in an invasion [27]. Adherence to biofilm formation can be a step preceding skin and GI colonization and can also involve surfaces of medical devices, other bacteria, and abiotic surfaces. Biofilms are often culprits involved in recurrences and efflux of anti-fungal medications, resulting in relapses and failed therapies. C. tropicalis adheres to a defibrillator, causing endocarditis and, after this, a biofilm that formed is a collection of microorganisms within an extracellular gel layer composed of proteins, lipids, and matrix [4,42]. It strengthens the adhesion between host cells or medical devices. Eventually, cells divide, reproduce, and further disseminate, causing widespread infection in different organs by the secretion of hydrolytic enzymes, hemolysins, secreted aspartyl proteases, and lipases. All of these are substantial virulence factors contributing to the widespread diseases associated with Candida species [27].

\section{Do drug use, hepatitis c, cardiac devices, prosthetic valve implants, and immunocompromised status augment the association between Candida and endocarditis?}

Despite being a normal human commensal, Candida can also switch and transform into a pathogenic yeast. Risk factors are abundant, creating a milieu for a systemic infection affecting the cardiac valves. Of the factors implicated in causation, the following are the ones discussed extensively: IVDU; cardiac devices and prosthetic valve implants; catheter-related infections; end-stage renal disease; hospital-acquired infections; and immunocompromised status. According to a recent case series study on IVDU and Candida endocarditis conducted in Massachusetts, there has been a resurgence of injection drug use and infective endocarditis. It is a severe risk factor to consider, as the study claimed that the patients who do IVDU often tend to be younger and have an association with hepatitis C [8]. This study also identified that IVDU patients had lesser incidence of HIV, but a prevalence of hepatitis C, possibly due to the associated increasing rates of hepatitis $\mathrm{C}$ in Massachusetts and decreasing rates of HIV. However, this study was limited to a specific region. Further studies might help to identify a stronger connection between hepatitis C and candidemia [8].

Drug Users and Candida Endocarditis

Having additional comorbidity with hepatitis $C$ the complicates the situation of these patients in the setting of an opioid epidemic. Also, the study conducted in Massachusetts reported that $C$. albicans was the third most common cause of infections in the IVDU population in central Massachusetts, preceded by $C$. parapsilosis and C. glabrata [8]. This is important since we know that different species of Candida are emerging as nosocomial pathogens, which further indicates that increased healthcare management, including the access to catheters, prosthetic valves, and prolonged antibiotic therapies increase the risk $[7,12,26-27,29]$. However, the findings may also indicate that IVDU in association with C. parapsilosis and C. glabrata outside of the hospital environment may act as community-acquired pathogens in the wake of a drug epidemic. Another common factor among many patients noted in the case reports and systematic review was diabetes $[4,8,23-24,27]$. Another vital risk factor was that many patients had either a structural or conduction defect in the heart that was strictly related to Candida endocarditis [17].

\section{Other risk factors}

The use of prosthetic valves, cardiac devices, and other modern procedures have contributed to the rising incidence of Candida endocarditis. An ICE and ICE-Plus trial found that prosthetic valve endocarditis was $50 \%$ more common in patients with candidemia when compared to non-fungal endocarditis. The same trial also concluded that patients with a prior history of endocarditis and cardiac surgery were more susceptible to this infection [10]. A 30-year study from 1965 to 1995 provided documented evidence on fungal endocarditis and brought into focus an essential discussion on many risk factors associated with fungal endocarditis [12]. Today, as the population is aging, the reported cases of prosthetic valve involvement, contamination of pacemakers and defibrillators, along with prolonged antibiotic therapy are at their peaks $[7,9,12,18,23]$. It explains, in part, the rise of Candida endocarditis in hospital- and non-hospital-acquired infections. In a majority of the cases, according to one review, endocarditis caused due to fungi often needed readmission. Added to this, injection drug users with a prosthetic valve or prior history of endocarditis are 
often significantly at risk as repeated injections of pathogens provide a way to cultivate growth on the valves directly [2]. In an observational cohort study based on the ICE trial from 2000 to 2010, congestive heart failure at baseline, persistent candidemia, and heart failure as complications also posed high-risk factors for mortality [17]. Even devices designed as roads to destination or transplantation therapy can be contaminated [20]. However, immunocompetent patients can also develop Candida endocarditis. A case report identified a 32-week primigravida who succumbed to mitral valve Candida endocarditis despite adequate medical and surgical management. The only known risk factor in her case was an appendicectomy conducted two months prior [21]. Collectively, these risk factors increase in-hospital mortality rates. In consideration of this, a validated risk score was developed, where host factors (hemodialysis), infective endocarditis characteristics (IE) such as prosthetic or nosocomial IE, left-sided endocarditis, and complications of IE such as heart failure, stroke, and persistent bacteremia displayed higher mortality as opposed to surgery for IE [1]. Further, the earlier surgical intervention helped in reducing complications and 6-month death rates [1]. Also, although the ICE study covered many geographic areas and locations where access to multidisciplinary care is available, the quality of care in remote areas with poor access to detection is a limitation [1]. In one study, it was also found that 30-day readmission trends were often high among the uninsured and they often left hospitals against medical advice, leading to delayed treatment and diagnosis [2].

\section{Anatomy}

Anatomically, the most common valves afflicted are the mitral and aortic valves $[10,11]$. These are valves that often undergo replacement or repair due to a primary aging condition. A study has identified that some type of prior insult to the heart is often present, which in this case are the multiple cardiac surgeries on the aortic, mitral, and tricuspid valves. The patient in this study also had significant immunosuppression (neutropenia) [38]. Another case report stated that Candida endocarditis may occur even after a TAVR [22]. Marked obstruction to the flow through the aorta and the extensive vegetations in blood cultures growing Candida parapsilosis as the causative agent questions the growing trend of non- albicans endocarditis; and the use of new surgical procedures can be detrimental and lead to infective endocarditis [22]. However, the location and association to a particular valve are dependent on a wide array of risk factors. For instance, a case report about C. albicans in a 75 -years-old female using subcutaneous catheter devices found that there was no valve involvement; it seemed that the right atrial septum was involved [15]. This rare case depicted the propensity of C. albicans to implant itself on any location of the endothelium [15]. Another case report supports this theory; this report depicted a foreign body, a fishbone, leading to left atrial C. albicans infective endocarditis as a result of its penetration through the esophagus [28]. Another study reported that approximately $16 \%$ of central venous catheters grew Candida species, causing endocarditis in right-sided valves predominantly [19].

\section{Management}

An essential tool for diagnosis remains an echocardiogram. Most likely, the lesions appear large and leftsided, often valvular. Transesophageal echocardiography, in contrast to transthoracic, is more sensitive and specific [39]. Guidelines for managing Candida endocarditis often incorporate both an urgent surgical and medical approach, in light of the fact that confining the treatment to medical therapy alone may cause embolic attacks, high morbidity, and mortality [39]. Medically, antifungal treatment is often part of the therapy. For example, polyene antifungals such as Amphotericin B create pores in the cell wall, resulting in loss of cytoplasmic content and cell death [27]. Lanosterol demethylase inhibitors such as fluconazole and voriconazole interfere with the synthesis of lanosterol to ergosterol, a key sterol in the cell wall $[13,27]$. These therapies, in combination with early debridement of all infected tissues, is usually performed to manage Candida endocarditis [40]. Further, a meta-analysis of cases from 1966 to 2002 confirmed lower mortality and a prevalence odds ratio (POR) of 0.56 with a $95 \%$ confidence interval (CI) of $(16,1.99)$ in patients receiving combined medical and surgical therapy. In contrast, medical treatment alone contributed to a higher death rate with a POR of 1.49 , and $95 \%$ CI of $(0.39,5.81)$ [43]. Possible causes of failure of medical treatment alone include relapses due to Candida species having the ability to form biofilms, which allow efflux of anti-fungal agents and decrease cell-wall penetration with resultant reduced action $[40,43]$.

However, there are many other challenges to consider in the treatment of Candida endocarditis. Some of them include geographic variations, virulence, and reduced susceptibility to antifungal medications [44]. As per the SENTRY Antimicrobial Surveillance Program (2008-2009), there is rising evidence of echinocandin (anidulafungin and micafungin) resistance emerging within C. glabrata due to FKS gene mutations [44]. Further, blood culture turnout time may affect earlier detection rates. Therefore, a high clinical suspicion must be maintained in vulnerable populations [45]. In fact, blood cultures are highly variable, providing an antemortem sensitivity rate of $21-71 \%$. This variability hampers the ability of blood cultures to efficiently detect viable cells of Candida so that they are quickly eliminated from the circulation, resulting in decreased sensitivity of the test [45]. Moreover, new rapid assays such as mannan and anti-mannan immunoglobulin G (IgG) have a combined sensitivity and specificity of 83 and $86 \%$, respectively [45]. Beta-D glucan assays and polymerase chain reactions (PCR) have been slower to be used for diagnosis but have indicated sensitivity close to $75 \%$. However, these rapid assays may not indicate actual evidence of Candida; but they indirectly help in diagnosing Candida endocarditis and should be considered earlier to establish a diagnosis [45]. Also, even patients with significant immunosuppression and neutropenia have better rates of detection than blood cultures with these new rapid assays [45]. Patients with neutropenia should also consider 
echinocandins, such as caspofungin and anidulafungin, as the initial therapy [40]. However, case reports from different institutions suggest management on a case-by-case basis, keeping in mind the severity, prognosis, and autonomy of the patient $[2,8,14-16]$. For example, according to an Italian study, prolonged antibiotic exposure and abdominal surgery more likely predisposed the patient to develop native valve endocarditis than prosthetic valve endocarditis [46]. Management of Candida endocarditis may often involve challenges and may lead to questionable treatment decisions, which may contribute to relapses.

Fluconazole, in particular, if given alone, contributes to high relapse rates [40]. However, fluconazole is considered a highly successful antifungal agent for relapses, life-long suppression, and recurrence of prosthetic valve endocarditis [40]. Susceptibility to medical treatment is dependent on the virulence of Candida species, which is measured by its ability to secrete aspartic peptidases (Saps) and produce biofilms. A prospective open-label clinical trial has shown the efficacy of caspofungin in the treatment of endocarditis due to its ability to penetrate biofilms [47]. The emergence of new guidelines and data will hopefully help us to easily convey pertinent points and critical risk factors as a guide to evidence-based medicine and contribute to the more efficient management of Candida endocarditis.

\section{Conclusions}

A review of the current literature has led us to conclude that there is a significant association in terms of the different risk factors associated with the pathogenesis of different Candida species. IVDU happens to be one of the significant risk factors associated with Candida endocarditis. Also, patients succumb to complications of congestive heart failure and embolism, and many do not fare well during the post-recovery period. Some solutions include setting up new programs that specialize in the long-term care of patients with Candida endocarditis. These programs can help address in-hospital morbidities, rehospitalizations, costs, and mortality. Questions that we propose today have many challenges and need urgent attention. For instance, how do we improve the one and 5 -year in-hospital morbidity and mortality rates? What steps should we take to improve the quality control of our institutions to reduce nosocomial infections? How should we detect Candida endocarditis in rural areas with poor access to health care? To address these challenges effectively, we should look for solutions collectively as we gain further insight into the association between Candida and endocarditis.

\section{Additional Information \\ Disclosures}

Conflicts of interest: In compliance with the ICMJE uniform disclosure form, all authors declare the following: Payment/services info: All authors have declared that no financial support was received from any organization for the submitted work. Financial relationships: All authors have declared that they have no financial relationships at present or within the previous three years with any organizations that might have an interest in the submitted work. Other relationships: All authors have declared that there are no other relationships or activities that could appear to have influenced the submitted work.

\section{References}

1. Park LP, Chu VH, Peterson G, et al.: Validated risk score for predicting 6-month mortality in infective endocarditis. J Am Heart Assoc. 2016, 5:e003016. Accessed: January 17, 2020: https://www.ncbi.nlm.nih.gov/pubmed/27091179. 10.1161/JAHA.115.003016

2. Pasupula DK, Bhat AG, Siddappa Malleshappa SK, et al.: Trends and predictors of 30-day readmission among patients hospitalized with infective endocarditis in the United States. Cureus. 2019, $11: \mathrm{e} 4962$. Accessed: January 17, 2020: https://www.cureus.com/articles/20853-trends-and-predictors-of-30-dayreadmission-among-patients-hospitalized-with-in.... 10.7759/cureus.4962

3. Murdoch DR, Corey GR, Hoen B, et al.: Clinical presentation, etiology and outcome of infective endocarditis in the 21st century: The International Collaboration on Endocarditis-Prospective Cohort Study. Arch Intern Med. 2009, 169:463-73. 10.1001/archinternmed.2008.603

4. Bauer BK, Schulze AB, Löher A, Reinke F, Eckardt L: Candida tropicalis defibrillator endocarditis: a case report and review of current literature. Med Mycol Case Rep. 2019, 25:1-9. Accessed: January 17, 2020: https://www.ncbi.nlm.nih.gov/pubmed/31245269. 10.1016/j.mmcr.2019.06.001

5. Lefort A, Chartier L, Sendid B, et al.: Diagnosis, management and outcome of Candida endocarditis . Clin Microbiol Infect. 2012, 18:E99-109. 10.1111/j.1469-0691.2012.03764.x

6. Ammannaya GKK, Sripad N: Fungal endocarditis: what do we know in 2019? . Kardiol Pol. 2019, 77:670-3. 10.33963/KP.14869

7. Jain AG, Guan J, D'Souza J: Candida parapsilosis: an unusual cause of infective endocarditis . Cureus. 2018, 10:e3553. Accessed: January 17, 2020: https://www.cureus.com/articles/13926-candida-parapsilosis-anunusual-cause-of-infective-endocarditis. 10.7759/cureus.3553

8. Poowanawittayakom N, Dutta A, Stock S, Touray S, Ellison RT 3rd, Levitz SM: Reemergence of intravenous drug use as risk factor for candidemia, Massachusetts, USA . Emerg Infect Dis. 2018, 24:10.3201/eid2404.171807

9. Ellis ME, Al-Abdely H, Sandridge A, Greer W, Ventura W: Fungal endocarditis: evidence in the world literature, 1965-1995. Clin Infect Dis. 2001, 32:50-62. 10.1086/317550

10. Baddley JW, Benjamin DK, Patel M, et al.: Candida infective endocarditis. Eur J Clin Microbiol Infect Dis. 2008, 27:519-29. 10.1007/s10096-008-0466-x

11. Falcone M, Barzaghi N, Carosi G, et al.: Candida infective endocarditis: report of 15 cases from a prospective multicenter study. Medicine (Baltimore). 2009, 88:160-8. 10.1097/MD.0b013e3181a693f8 
12. Silva S, Negri M, Henriques M, Oliveira R, Williams DW, Azeredo J: Candida glabrata, Candida parapsilosis and Candida tropicalis: biology, epidemiology, pathogenicity and antifungal resistance. FEMS Microbiol Rev. 2012, 36:288-305. 10.1111/j.1574-6976.2011.00278.x

13. Talarmin JP, Boutoille D, Tattevin P, Abgueguen P, Ansart S, Roblot F, Raffi F: Candida endocarditis: role of new antifungal agents. Mycoses. 2009, 52:60-6. 10.1111/j.1439-0507.2008.01533.x

14. Toyoda S, Tajima E, Fukuda R, et al.: Early surgical intervention and optimal medical treatment for Candida parapsilosis endocarditis. Intern Med. 2015, 54:411-3. 10.2169/internalmedicine.54.2989

15. Chowdhury W, Lodhi MU, Syed IA, Rahim U, Miller M, Rahim M: Catheter-related Candida endocarditis on the right atrial septum - a case report . Cureus. 2018, 10:e2158. Accessed: January 17, 2020: https://www.cureus.com/articles/10852-catheter-related-candida-endocarditis-on-the-right-atrial-septum--a-case-report. 10.7759/cureus.2158

16. Bandyopadhyay S, Tiwary PK, Mondal S, Puthran S: Pacemaker lead Candida endocarditis: Is medical treatment possible?. Indian Heart J. 2015, 67:S100-2. 10.1016/j.ihj.2015.11.025

17. Arnold CJ, Johnson M, Bayer AS, et al.: Candida infective endocarditis: an observational cohort study with a focus on therapy. Antimicrob Agents Chemother. 2015, 59:2365-73. 10.1128/AAC.04867-14

18. Shokohi T, Nouraei SM, Afsarian MH, Najafi N, Mehdipour S : Fungal prosthetic valve endocarditis by candida parapsilosis: a case report. Jundishapur J Microbiol. 2014, 7:e9428. 10.5812/jjm.9428

19. Chrissoheris MP, Libertin C, Ali RG, Ghantous A, Bekui A, Donohue T: Endocarditis complicating central venous catheter bloodstream infections: a unique form of health care associated endocarditis. Clin Cardiol. 2009, 32:E48-54. 10.1002/clc.20498

20. Maly J, Szarszoi O, Dorazilova Z, Besik J, Pokorny M, Kotulak T, Netuka I: Case report: atypical fungal obstruction of the left ventricular assist device outflow cannula. J Cardiothorac Surg. 2014, 9:40. Accessed: January 17, 2020: https://www.ncbi.nlm.nih.gov/pubmed/24565328. 10.1186/1749-8090-9-40

21. Saphina P, Mansoor CA, Jemshad A, Musambil M: Native valve Candida endocarditis complicating pregnancy after abdominal surgery. Heart Views. 2015, 16:111-3. 10.4103/1995-705X.164459

22. Carrel T, Eberle B: Candida Endocarditis after TAVR. N Engl J Med. 2019, 380:e1. 10.1056/NEJMicm1809948

23. Barchiesi F, Orsetti E, Mazzanti S, Trave F, Salvi A, Nitti C, Manso E: Candidemia in the elderly: what does it change?. PLoS One. 2017, 12:e0176576. Accessed: January 17, 2020: https://www.ncbi.nlm.nih.gov/pubmed/28493896. 10.1371/journal.pone.0176576

24. Rivera NT, Bray N, Wang H, Zelnick K, Osman A, Vicuña R: Rare infection of implantable cardioverterdefibrillator lead with Candida albicans: case report and literature review. Ther Adv Cardiovasc Dis. 2014, 8:193-201. 10.1177/1753944714539406

25. Zahid MA, Klotz S, Hinthorn DR: Medical treatment of recurrent candidemia in a patient with probable Candida parapsilosis prosthetic valve endocarditis. Chest. 1994, 105:1597-8. 10.1378/chest.105.5.1597

26. Pyrgos V, Ratanavanich K, Donegan N, Veis J, Walsh TJ, Shoham S: Candida bloodstream infections in hemodialysis recipients. Med Mycol. 2009, 47:463-7. 10.1080/13693780802369332

27. De Rosa FG, D'Avolio A, Corcione S, et al.: Anidulafungin for Candida glabrata infective endocarditis . Antimicrob Agents Chemother. 2012, 56:4552-3. 10.1128/AAC.00515-12

28. Tong YL, Qu TT, Xu J, Chen NY, Yang MF: Successful treatment of an acute infective endocarditis secondary to fish bone penetrating into left atrium caused by Granulicatella adiacens and Candida albicans: a case report. Medicine (Baltimore). 2017, 96:e9185. 10.1097/MD.0000000000009185

29. Merseguel KB, Nishikaku AS, Rodrigues AM, et al.: Genetic diversity of medically important and emerging Candida species causing invasive infection. BMC Infect Dis. 2015, 15:57. Accessed: January 17, 2020: https://www.ncbi.nlm.nih.gov/pubmed/25887032. 10.1186/s12879-015-0793-3

30. Jackson AP, Gamble JA, Yeomans T, et al.: Comparative genomics of the fungal pathogens Candida dubliniensis and Candida albicans. Genome Res. 2009, 19:2231-44. 10.1101/gr.097501.109

31. Brunke S, Hube B: Two unlike cousins: Candida albicans and C. glabrata infection strategies . Cell Microbiol. 2013, 15:701-8. 10.1111/cmi.12091

32. Pärnänen P, Meurman JH, Nikula-Ijäs P: A novel Candida glabrata cell wall associated serine protease . Biochem Biophys Res Commun. 2015, 457:676-80. 10.1016/j.bbrc.2015.01.047

33. Sullivan D, Coleman D: Candida dubliniensis: characteristics and identification. J Clin Microbiol. 1998, 36:329-34.

34. Trofa D, Gácser A, Nosanchuk JD: Candida parapsilosis, an emerging fungal pathogen. Clin Microbiol Rev. 2008, 21:606-25. 10.1128/CMR.00013-08

35. Rodrigues CF, Silva S, Henriques M: Candida glabrata: a review of its features and resistance . Eur J Clin Microbiol Infect Dis. 2014, 33:673-88. 10.1007/s10096-013-2009-3

36. Okawa Y, Goto K: Antigenicity of Candida tropicalis strain cells cultured at 27 and $37^{\circ} \mathrm{C}$. FEMS Immunol Med Microbiol. 2006, 46:438-43. 10.1111/j.1574-695X.2006.00056.x

37. Fidel PL Jr, Vazquez JA, Sobel JD: Candida glabrata: review of epidemiology, pathogenesis, and clinical disease with comparison to C. albicans. Clin Microbiol Rev. 1999, 12:80-96.

38. Martino P, Girmenia C, Micozzi A, Raccah R, Gentile G, Venditti M, Mandelli F: Fungemia in patients with leukemia. Am J Med Sci. 1993, 306:225-32. 10.1097/00000441-199310000-00004

39. Evangelista A, Gonzalez-Alujas MT: Echocardiography in infective endocarditis. Heart. 2004, 90:614-7. 10.1136/hrt.2003.029868

40. Pappas PG, Kauffman CA, Andes DR, et al.: Clinical practice guideline for the management of candidiasis: 2016 update by the Infectious Diseases Society of America. Clin Infect Dis. 2016, 62:e1-50. $10.1093 / \mathrm{cid} / \mathrm{civ} 933$

41. Negri M, Martins M, Henriques M, Svidzinski TI, Azeredo J, Oliveira R: Examination of potential virulence factors of Candida tropicalis clinical isolates from hospitalized patients. Mycopathologia. 2010, 169:175-82. 10.1007/s11046-009-9246-0

42. Ramage G, Martínez JP, López-Ribot JL: Candida biofilms on implanted biomaterials: a clinically significant problem. FEMS Yeast Res. 2006, 6:979-86. 10.1111/j.1567-1364.2006.00117.x

43. Steinbach WJ, Perfect JR, Cabell CH, et al.: A meta-analysis of medical versus surgical therapy for Candida endocarditis. J Infect. 2005, 51:230-47. 10.1016/j.jinf.2004.10.016 


\section{Cureus}

44. Pfaller MA, Moet GJ, Messer SA, Jones RN, Castanheira M: Geographic variations in species distribution and echinocandin and azole antifungal resistance rates among Candida bloodstream infection isolates: report from the SENTRY Antimicrobial Surveillance Program (2008 to 2009). J Clin Microbiol. 2011, 49:396-9.

10.1128/JCM.01398-10

45. Clancy CJ, Nguyen MH: Finding the "missing 50\%" of invasive candidiasis: how nonculture diagnostics will improve understanding of disease spectrum and transform patient care. Clin Infect Dis. 2013, 56:1284-92. 10.1093/cid/cit006

46. Giuliano S, Guastalegname M, Russo A, et al.: Candida endocarditis: systematic literature review from 1997 to 2014 and analysis of 29 cases from the Italian Study of Endocarditis. Expert Rev Anti Infect Ther. 2017, 15:807-18. 10.1080/14787210.2017.1372749

47. Cornely OA, Lasso M, Betts R, et al.: Caspofungin for the treatment of less common forms of invasive candidiasis. J Antimicrob Chemother. 2007, 60:363-9. 10.1093/jac/dkm169 